\title{
The Vulnerable red panda Ailurus fulgens in Bhutan: distribution, conservation status and management recommendations
}

\author{
Sangay Dorji, Rajanathan Rajaratenam and Karl Vernes
}

\begin{abstract}
The red panda Ailurus fulgens is categorized as Vulnerable on the IUCN Red List. Pressurized by an expanding human population, it is mainly threatened by habitat destruction, with $<10,000$ mature individuals remaining. The red panda has been studied in India, China, Nepal and, to a lesser extent, Myanmar, but no research has been published on this species in Bhutan. Here, we report on the current distribution and conservation status of the red panda in Bhutan using information gathered from field surveys, interviews and unpublished reports. Red pandas are most common at 2,400-3,700 m altitude in fir Abies densa forests with an undergrowth of bamboo. They occur in most national parks and associated biological corridors within Bhutan's protected area network, overlapping with a rural human population that is undergoing increased socioeconomic development. Although culturally respected, red pandas face threats from road construction, harvesting of timber, bamboo and minor forest products, livestock grazing, inefficiently managed tourism, and domestic dogs. We believe conservation of red pandas in Bhutan requires (1) inclusion of ecologically sound principles into future development, (2) implementation of programmes that improve rural socio-economy through ecotourism and cultivation of appropriate cash crops, (3) development of education programmes that raise awareness of red pandas for rural people, (4) management of rural dog populations, (5) greater capacity building for wildlife managers, and (6) more ecological research.
\end{abstract}

Keywords Ailurus fulgens, bamboo, Bhutan, eastern Himalayas, protected areas, red panda, temperate coniferous forest, wildlife management

SANGAY DORJI ${ }^{*}$ and KARL VERNES Ecosystem Management, University of New England, Armidale, New South Wales, Australia

RAJANATHAN RAJARATNAM (Corresponding author) Geography and Planning, University of New England, Armidale, New South Wales, Australia. E-mail rrajarat@une.edu.au

${ }^{*}$ Also at: Wildlife Conservation Division, Department of Forests and Park Services, Ministry of Agriculture and Forests, Bhutan

Received 6 January 2011. Revision requested 7 March 2011. Accepted 5 April 2011.

\section{Introduction}

The red panda Ailurus fulgens is a threatened mammal 1 restricted to temperate and sub-tropical forests of the eastern Himalayas, with the exception of a tropical forest population in Meghalaya, India (Choudhury, 2001). Its distribution ranges from western $\mathrm{Nepal}\left(82^{\circ} \mathrm{E}\right)$ into India, Bhutan and northern Myanmar through to the Minshan Mountains and upper Min Valley of Sichuan Province in south-central China $\left(104^{\circ} \mathrm{E}\right)$ (Wei et al., 1999c; Choudhury, 2001; Fig. 1). The red panda occurs as two subspecies that are biogeographically separated by the Salween (Nu Jiang) River in China (Choudhury, 2001; Wang et al., 2008). A. f. fulgens occurs in the west in Bhutan, Nepal, India, northern Myanmar and China (southern Tibet and western Yunnan) and A. f. styani occurs in the east, in south-central China (Sichuan and Yunnan). The distribution of the red panda is disjunct across this range (Roberts \& Gittleman, 1984). The population on the Meghalaya Plateau of north-eastern India is isolated by the Brahmaputra River (Choudhury, 2001), and local extinctions have been reported in Guizhou, Gansu, Shaanxi and Qinghai provinces of China (Wei et al., 1999c). In Langtang National Park, Nepal, the red panda persists in four subpopulations (Yonzon et al., 1991).

In the eastern Himalayas the red panda lives at altitudes of 1,500-4,800 $\mathrm{m}$ (Choudhury, 2001), with an affinity for habitats with dense bamboo undergrowth (Choudhury, 2001; Zhang et al., 2006). They mainly feed on bamboo, with supplements of fruit, roots, succulent grasses, mushrooms, acorns and lichens, and occasional bird eggs, insects and grubs (Reid et al., 1991; Yonzon \& Hunter, 1991b; Pradhan et al., 2001a; Nath \& Das, 2010). Fallen logs, tree stumps and shrubs are important habitat elements for red pandas (Pradhan et al., 2001a; Zhang et al., 2006), providing substrates suitable for defecation (Pradhan et al., 2001a) and structural access to bamboo leaves (Johnson et al., 1988; Reid et al., 1991; Wei et al., 1999c). Water availability also seems to be important, to supplement the low water content of bamboo leaves (Yonzon \& Hunter, 1991b; Pradhan et al., 2001a).

Choudhury (2001) estimated a global red panda population of 16,000-20,000 based on the lowest recorded density of one individual per $4.4 \mathrm{~km}^{2}$ in Langtang National Park, Nepal (Yonzon \& Hunter, 1987). He 


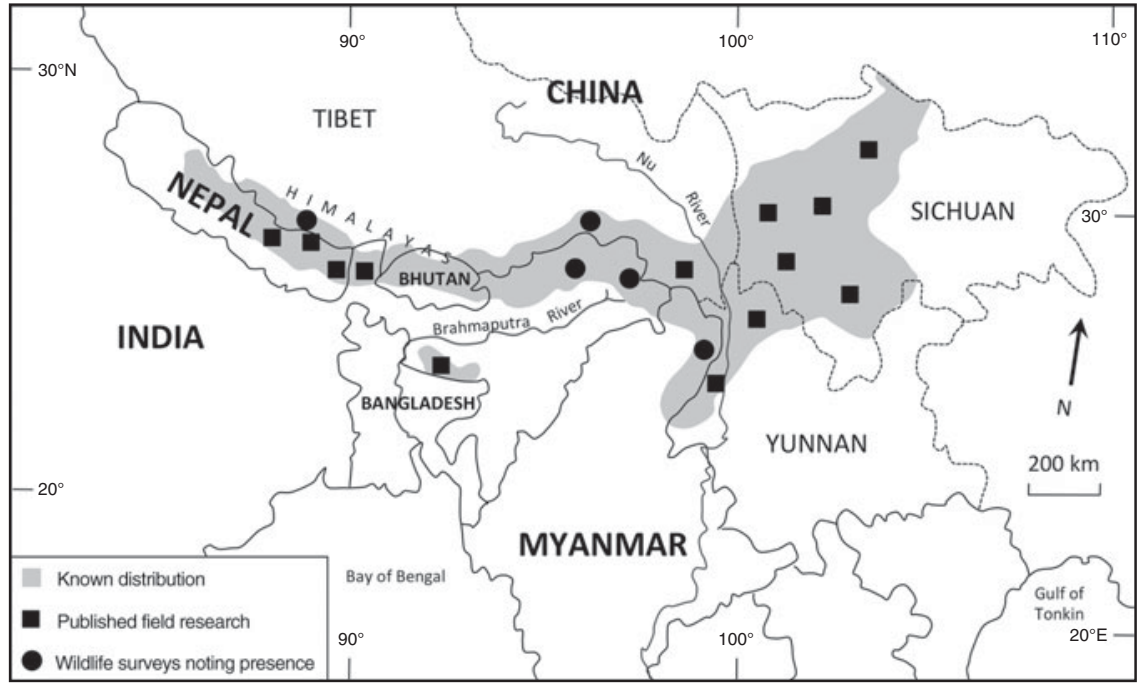

FIG. 1 Distribution of the red panda Ailurus fulgens in South Asia (modified from Choudhury, 2001), showing locations covered by published research focusing on the species and the locations of published wildlife surveys that noted the species' presence. further subdivided this estimate among the range countries: 5,000-6,000 in India, c. 6,000-7,000 in China, and a combined population of c. 5,000-7,000 across Nepal, Myanmar and Bhutan. However, Wang et al. (2008) estimated the global population to be $<10,000$ mature individuals.

The red panda is threatened by habitat loss and fragmentation resulting from cumulative overuse of resources by an expanding human population (Liang \& Zhang, 1987; Yonzon \& Hunter, 1991b; Glatston, 1994; Wei et al., 1999c; Choudhury, 2001; Pradhan et al., 2001a; Williams, 2003; Han \& Hu, 2004; Yang, 2008; Nath \& Das, 2010). Ancillary threats include poaching, domestic dogs, climate change, and killing by local people and poachers (Yonzon \& Hunter, 1991b; Glatston, 1994; Rabinowitz \& Khaing, 1998; Wei et al., 1999c; Choudhury, 2001). The species is categorized as Vulnerable on the IUCN Red List (Wang et al., 2008) based on the low global population estimate and a projected decline in numbers of $>10 \%$ over the next three generations (estimated at 30 years). It is also listed in Appendix I of CITES (CITES, 2010) and protected by law in all range countries.

Published information on the red panda is limited to studies conducted in India, China and Nepal. Choudhury (2001) discussed the global distribution and population status of the red panda with special reference to India. There have been studies in China on habitat selection, diet, reproduction, home range, phylogeny, distribution and conservation status (Gittleman, 1988; Johnson et al., 1988; Reid et al., 1991; Wei et al., 1999a,b,c,d, 2000a,b; Li et al., 2005; Jiandong et al., 2006; Zhang et al., 2006, 2009). Additional studies on ecology, distribution and population status of the red panda have been carried out in India and Nepal (Yonzon et al., 1991; Yonzon \& Hunter, 1991a,b; Choudhury, 2001; Pradhan et al., 2001a,b; Williams, 2003; Mahato, 2004; Adhikari, 2010; Nath \& Das, 2010).
Information on the red panda in Myanmar is based solely on a note in Rabinowitz \& Khaing's (1998) report on the status of mammals.

Here we report on the distribution and conservation status of the red panda in Bhutan and make recommendations for appropriate conservation measures. This research, the first on the red panda in the country, is important for conservation programmes and management strategies in Bhutan as well as for the global knowledge on this Vulnerable species.

\section{Methods}

We assessed the distribution and status of the red panda in Bhutan from field surveys, biodiversity survey and management reports, government documents, and interviews with national park residents and park staff. Field surveys, comprising interviews and ecological monitoring, were conducted between 2007 and 2009 and provided presenceabsence data on the red panda in two of Bhutan's protected areas: Thrumshingla and Jigme Dorji National Parks. We interviewed 664 park residents from various occupational groups comprising farmers, herders, road workers, school children, teachers, civil servants, monks, and park and forestry officials. We also interviewed an additional 48 officials from other national parks. Interviews gathered location data on red pandas and assessed cultural significance and conservation threats. Based on preliminary surveys over 127 days we established and monitored plots $(20 \times 20 \mathrm{~m})$ in potential red panda habitat in Thrumshingla National Park $(n=87)$ and Jigme Dorji National Park $(n=64)$ over a further 178 days to detect red pandas by sightings and droppings. In addition to our study sites we also conducted surveys in several other potential red panda areas: Ramina, Dolamkencho and Jabisa in Jigme Dorji National Park; Chungphel, Bim, Tharpaling, 


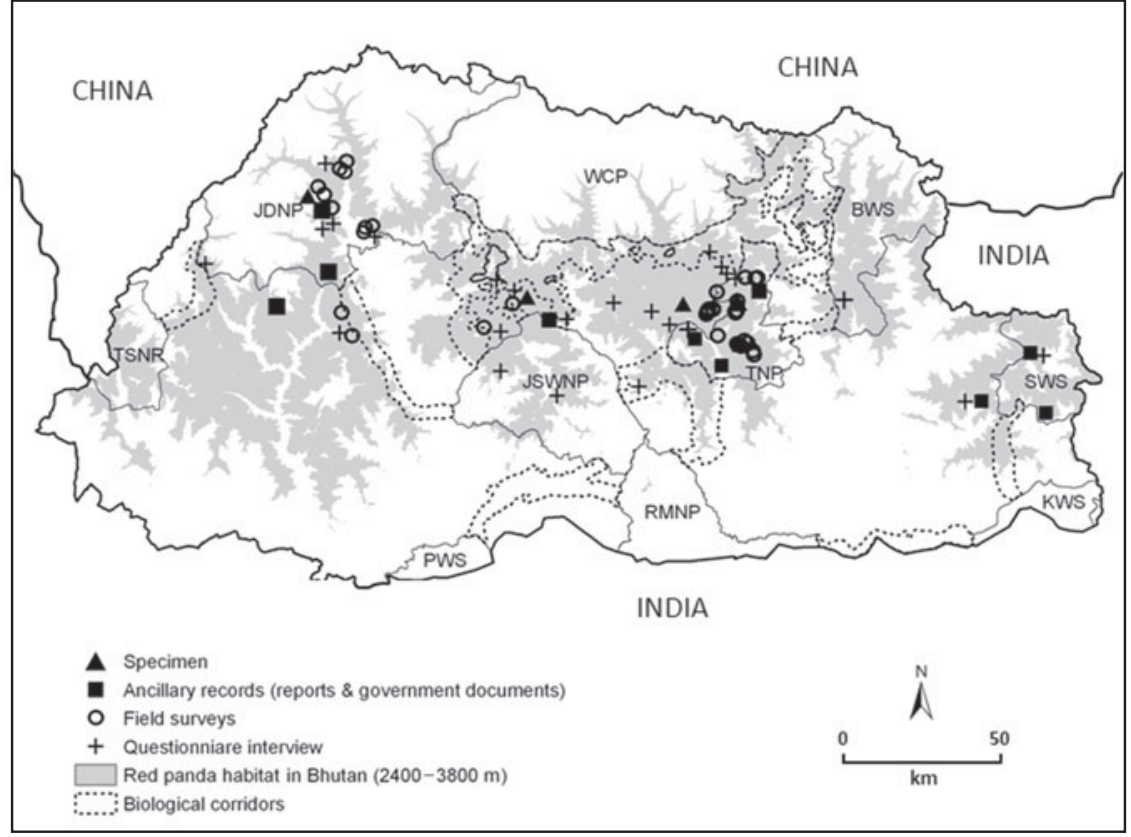

FIG. 2 Distribution of the red panda within the protected area system of Bhutan. TSNR, Toorsa Strict Nature Reserve; JDNP, Jigme Dorji National Park; WCP, Wangchuck Centennial Park; BWS, Bumdeling Wildlife Sanctuary; JSWNP, Jigme Singye Wangchuck National Park; TNP, Thrumshingla National Park; SWS, Sakteng Wildlife Sanctuary; KWS, Khaling Wildlife Sanctuary; RMNP, Royal Manas National Park; PWS, Phibsoo Wildlife Sanctuary.
Karshong, Tang, Rodungla and Chume in Thrumshingla National Park; Chendepji, Pelela, Kheybethang and Lawala in Jigme Singye Wangchuck National Park; and Yotongla in Trongsa district. Location data were recorded by a global positioning system and plotted using ArcGIS v. 9.3 (ESRI, Redlands, USA).

\section{Results}

\section{Distribution and habitat association}

Occurrence of the red panda was confirmed in 13 districts (Haa, Thimphu, Paro, Punakha, Wangdiphodrang, Gasa, Trongsa, Zhemgang, Bumthang, Mongar, Lhuntse, Trashigang and Trashiyangtse; Dorjee, 2009; Dorji, 2009; this study). High elevation areas in other districts (Chukha, Tsirang, Dagana, Samtse and Samdrupjongkhar) require further surveys.

Within Bhutan's protected area network the occurrence of the red panda was confirmed in Jigme Dorji, Thrumshingla and Jigme Singye Wangchuck National Parks, Bumdeling and Sakteng Wildlife Sanctuaries, Toorsa Strict Nature Reserve, biological corridors connecting these reserves, and the biological corridor connecting Thrumshingla and Royal Manas National Parks (Dorjee, 2009; Dorji, 2009; this study; Fig. 2). The red panda has also been recorded in the Royal Botanical Park (Sherap Wangchuk, Senior Park Ranger, pers. comm.), Khaling Wildlife Sanctuary and Wangchuck Centennial Park (Dorji, 2009). Within Thrumshingla National Park red pandas were confirmed at Wangthangla, Ura, Shingkhar, Gyazamchu, Thrumshingla, Sengore, Latongla, Piscula,
Chumee, Khanzoo, Pimi, Phokpai, Tang, Thekpaling, Murgang and Gyazamphok. Within Jigme Dorji National Park, red pandas were confirmed in Gasa, Chamsa, Koina, Gomodharchasa, Damji, Jabisa, Phuntshogang, Yemina, Dolamkencho, Tshepgang, Tokchu, Gayza, Zamizam and Ramina.

Red pandas occur in temperate forests at 2,000-4,300 $\mathrm{m}$ altitude (Dorji, 2009) but are more common at 2,400-3,700 m in coniferous fir Abies densa forests with undergrowth of the bamboos Yushania microphylla, Yushania maling, Thamnocalamus spathiflorus and Arundinaria. The panda also occurs in cool broadleaved forests with an undergrowth of the bamboos Yushania hirsuta, Drepanostachyum annulatum, Borinda grossa and Thamnocalamus spathiflorus. In both forest types evidence of the red panda was detected around fruiting trees such as Sorbus microphylla, Sorbus cuspidata, Sorbus lanata, Sorbus foliolosa, Rosa sericea, Ribes spp., Hyelbolia spp. and Verbernum spp.. In Thrumshingla National Park red pandas were detected in spruce Picea spinulosa and hemlock Tsuga dumosa dominated coniferous forests.

\section{Awareness and cultural significance}

The red panda's distribution overlaps substantially with the human population in Bhutan. However, questionnaire surveys of park residents (Thrumshingla and Jigme Dorji National Parks combined, $\mathrm{n}=664$ ) revealed a lack of awareness about the red panda, especially among farmers, monks, road workers and students (Fig. 3). Most respondents $(\mathrm{n}=93 ; 70 \%$ in Jigme Dorji National Park; $\mathrm{n}=271$; $68 \%$ in Thrumshingla National Park) knew nothing about 


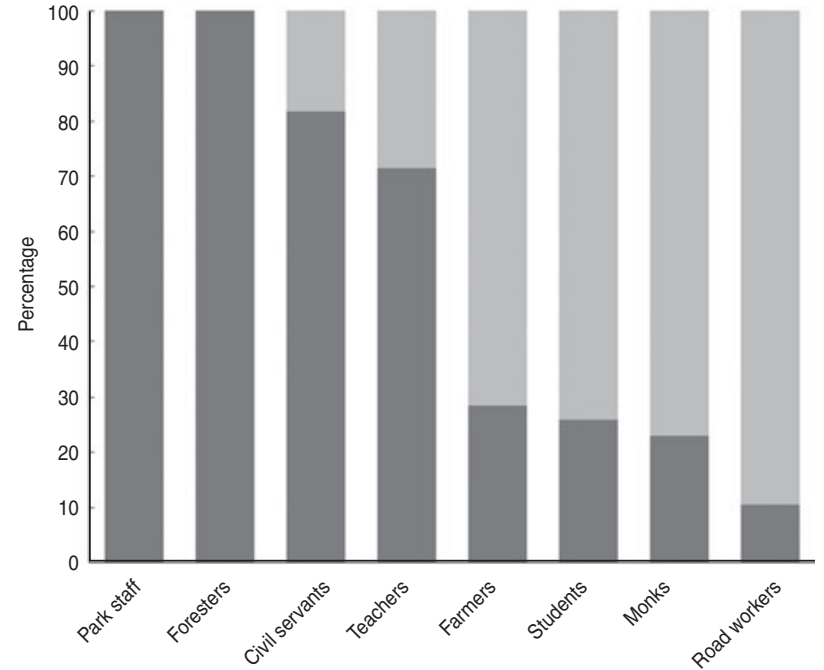

FIG. 3 Degree of awareness (dark grey) or lack of awareness (light grey) of red pandas, as determined from questionnaire interviews with park residents in Jigme Dorji and Thrumshingla National Parks (Fig. 2).

the red panda. Many respondents who claimed knowledge of the species $(n=130)$ could not identify it, often confusing it with morphologically similar species such as the red fox Vulpes vulpes, dhole Cuon alpinus, yellow throated marten Martes flavigula, Himalayan weasel Mustella sibirica and Malayan giant squirrel Ratufa bicolor.

Respondents who could identify the red panda (mainly elderly farmers and cattle herders; $n=31$ ) placed great cultural significance on the species. People of Bumthang and Sengore in Thrumshingla National Park believed the red panda to be a reincarnation of a Buddhist monk, equating its red fur to the red robe of a monk. In Jigme Dorji National Park people of Gasa, Punakha, Thimphu and Paro Districts considered its sighting to be a good omen, with some respondents narrating positive experiences ranging from acquiring wealth (more land, a bigger house), increased selfsufficiency from a relatively meagre existence, to job promotions. However, most park and forestry staff, civil servants, road workers, teachers and school children $(n=462)$ were unaware of the red panda's cultural importance.

\section{Discussion}

\section{Habitat destruction}

The expanding road network is affecting Bhutan's wilderness. The network increased by $>50 \%$ (from 3,215 to 4,946.6 km) between 2002 and 2008 (National Statistics Bureau of Bhutan, 2009), an average increase of nearly 300 $\mathrm{km}$ per year. During the same period $800 \mathrm{~km}$ of farm roads and $173 \mathrm{~km}$ of power tiller tracks were constructed (RNR Engineering Division, 2008) and a further $480 \mathrm{~km}$ of new roads are planned for construction by 2013. This fragments and opens up otherwise inaccessible red panda habitat for further development and results in the felling of mature trees and destruction of bamboo undergrowth, all of which have direct impacts on red pandas, especially in Thrumshingla and Jigme Dorji National Parks (Dorji, 2009).

Traditional houses in Bhutan are built of timber and a government policy of retaining traditional architecture in all construction will continue to affect forests. For example, from 2001 to $2005>1,300$ ha of forest was cleared for infrastructure development and agricultural production (Royal Government of Bhutan, 2009). The Forest and Nature Conservation Rule (Bhutan) 2006 allows each rural household an annual timber harvest equivalent to 30 mature trees for new construction, maintenance, roofing, fencing, firewood and prayer flagpoles. As 65\% of Bhutan's households are in rural areas potential red panda habitat is exploited to meet these demands. There is also a demand from urban areas for timber and firewood, particularly in major districts such as Thimphu, Phuntsholing, Paro, Bumthang, Wangduephodrang, Samdrupjongkhar and Gelephu.

Rural Bhutanese are dependent on forest resources for their livelihoods (Tshering, 2009), with rural poverty both the cause and effect of much environmental degradation through a reliance on livestock (Norbu, 2000; Royal Government of Bhutan, 2009). Although cattle numbers have increased by only $3.5 \%$ since 1990 , yak populations have increased by 55.9\% (Royal Government of Bhutan, 2009). Grazing of cattle, yak, sheep and horses (mainly upon bamboo) in forests is inevitable (Roder et al., 2002) as $<2 \%$ of Bhutan's area is suitable for pasture. Grazing, with felling, girdling, looping and trampling are significant threats to red panda habitat in Bhutan's protected areas (Dorjee, 2009; Dorji, 2009). Bamboo harvesting is a particular threat to red pandas (Messerchmidt et al., 2001). Almost $42 \%$ of households in Bhutan use bamboo for roofing, thatching, fencing, baskets, arrows, containers and other handicrafts (Ministry of Agriculture, 2000). Rural residents also collect resin, fungi, medicinal plants, orchids, rattan and ferns (Dorji, 2009).

\section{Tourism}

Tourism is growing rapidly in Bhutan, increasing from 21,094 tourists in 2007 to 27,636 in 2008 (i.e. $30 \%$; National Statistics Bureau of Bhutan, 2009). The government's longterm goal is 100,000 tourists per year (Kuenselonline, 2010). Tourism activities tend to be focussed in red panda habitat (authors, pers. obs.). Trekking is especially popular in Jigme Dorji National Park, with its famous Jomolhari, Laya and Snowmen treks (Dorji, 2009), and pack horses used by trekkers increase the grazing and trampling of bamboo 
undergrowth in potential red panda habitat (authors, pers. obs.). Tourism activities also directly affect forest timber resources (Gurung \& Scholz, 2008). Glatston (1994) estimated that a western tourist visiting the range of the red panda uses more firewood in 1 week than a local person does in 1 year. Other negative impacts from tourism include collection of timber for infrastructure development (Gurung \& Scholz, 2008).

\section{Hunting}

Hunting of red pandas in Bhutan is non-existent (Dorjee, 2009; Dorji, 2009). Examination of official records of illegal activity in Jigme Dorji and Thrumshingla National Parks revealed no cases involving hunting of red pandas. Historically, people of Shingkhar, Sengore and Chume in Thrumshingla National Park, and Soe in Jigme Dorji National Park used red panda fur to make hats but this no longer occurs (Dorji, 2009). Inadvertent killing of red pandas by poachers seeking prized musk deer Moschus chrysogaster and pheasants could, however, be a threat. During our surveys in Jigme Dorji and Thrumshingla National Parks we found numerous snares for musk deer and pheasants in areas used by red pandas. This is further corroborated by a resident of Gasa, Jigme Dorji National Park who officially reported a red panda trapped in a musk deer snare (Dorji, 2009).

\section{Domestic dogs}

Livestock herders in Bhutan keep domestic dogs to deter wild predators. These dogs roam freely in the forest and are a prominent threat to red pandas. We regularly saw dogs at widely dispersed road workers' camps in Thrumshingla and Jigme Dorji National Parks. During our questionnaire surveys respondents in these two Parks noted having seen domestic dogs attack red pandas. Villagers in Sengore and Shingkhar in Thrumshingla National Park recalled rescuing red pandas from dogs in the early 1990s. In 2008 Thrumshingla National Park staff rescued a red panda from dogs, releasing it deeper into the Park. We observed red panda fur in Gaiden Lhakhang in Ura and were told that it resulted from a kill by domestic dogs. In addition to predation and potential disruption of maternal behaviour, dogs are known carriers of canine distemper, which is fatal to red pandas (Deem et al., 2000).

\section{Conservation recommendations}

Roads Bhutan's protected area network and biological corridors (Fig. 2) maintain $72 \%$ of the country under permanent forest cover (Dorji, 2009). Although justified socio-economically, extension of the road network within protected areas needs to follow a master plan that incorporates environmental impact assessments to offset habitat fragmentation. Planning is required to ensure the integrity of red panda habitat within temperate conifer forests and conserving pristine red panda habitat is essential for managing watershed catchments. A study of the environmental impact of road construction in Bhutan's wildlife rich forests is required (Dorji, 2009). Proposed roads through prime red panda habitat (e.g. from Gasa to Laya in Jigme Dorji National Park, and between Gayza and Zamizam, and Dodena and Lingshi) are of particular concern.

Rural socio-economy Approximately $23 \%$ of Bhutan's population live below the poverty line (BTN 1,100, or USD 25 , per person per month) with $97 \%$ of these people living in rural areas (National Statistics Bureau of Bhutan, 2009). Rural socio-economy must be improved to reduce consumptive pressure on forest resources in red panda habitat. Alternative sustainable means of livelihood identified by the integrated conservation and development programme (ICDP) run by the Department of Forests and Park Services should be encouraged. Community-based activities such as organic farming, beekeeping, medicinal plant cultivation, growing high value-low volume cash crops such as soft shell walnuts and hazelnuts, cultivation of ornamental orchids and rhododendrons, and the sale of local crafts to tourists would minimize pressure on timber, bamboo and other forest resources.

Tourism Tourism in Bhutan is government regulated but commercially operated. It emphasizes cultural experiences, scenic views and trekking, with negligible benefits to rural communities (authors, pers. obs.). The red panda is an ideal iconic and charismatic species for promoting wildlife tourism, which could benefit the species, as successfully demonstrated for the orang-utan Pongo pygmaeus in Borneo (Rajaratnam et al., 2008). The species is regionally prominent as the national animal of Sikkim and the mascot for the Darjeeling Tea Festival (Dorji, 2009), and could be a flagship species for wildlife tourism in Bhutan. Developing village-based wildlife tourism to supplement existing ICDP activities could integrate conservation of the red panda into the rural economy. With preliminary financial support, infrastructure development, training and marketing, villagers in prime red panda areas such as Thrumshingla and Jigme Dorji National Parks could be encouraged to take stewardship of the red panda, supported by a wildlife tourism master plan to promote environmentally sustainable tourism practices.

Habitat zonation Areas in Jigme Dorji and Thrumshingla National Parks require special designation and protection as core zones for the red panda. Management protocols are required for collection of forest resources and livestock 
grazing in these areas during the breeding season of the red panda. Areas requiring such focus in Jigme Dorji National Park are between Gomodharchasa and Zamizam, between Chamsa and Koina, and around Dolam Kencho and Ramina. Critical areas in Thrumshingla National Park include Sengore, Thrumshingla, Wangthangla, Magoenpa and Fiscula. Increased patrols in these areas are needed to curb poaching of musk deer and pheasants.

Education Given the low awareness of red pandas, a conservation education programme needs to be initiated and implemented cooperatively between relevant government institutions (Department of Forests and Park Services, Ugyen Wangchuck Institute for Conservation and Environment and the Ministry of Education) and NGOs (WWF Bhutan, Bhutan Trust Fund and the Royal Society for Protection of Nature and Natural Resources), with emphasis on areas identified as red panda strongholds. Programmes could prioritize school curriculum development, focusing on Bhutan's rich and unique wildlife.

Dogs Culling of dogs runs counter to Bhutan's Buddhist ethos. The Ministry of Agriculture is, however, carrying out widespread sterilization of dogs. In addition, awareness of the impacts of dogs is required, in coordination with relevant departments such as the Ministry of Works and Human Settlements, and district administrations. Sterilization should be ongoing, to maintain dog populations at the desired level, with concurrent vaccination against canine distemper. In designated core zones within protected areas, there should be a requirement to register dogs with park authorities and measures to quarantine stray animals.

Research, capacity building and conservation funding Further surveys and ecological research on the red panda are needed, focusing on spatial and social organization, effects of climate change, habitat status, and anthropogenic impacts. Research on the impacts of dogs on wildlife and of local perceptions of dog control are also required. Given the red panda's cryptic nature, training in appropriate research methodology for protected area managers and local researchers is required. There is a will in Bhutan to implement effective wildlife conservation but a lack of adequate funding to do so. Biological conservation is firmly rooted in Buddhist philosophy and encompassed by government policies, and this has resulted in an effective protected area network under natural forest cover. Funding should focus on enhancing research on the red panda because it has been proposed as a suitable indicator species for monitoring the integrity of the Eastern Himalayan Broadleaf and Conifer Ecoregion (Williams, 2003) and has considerable overlap with the distribution of humans in Bhutan (Dorji et al., 2011).
Most of these recommendations have been presented to the relevant stakeholders. Measures such as controlling dog populations, zoning of protected areas and taking an environmental approach to road construction within protected areas are being implemented. The government is currently drafting its 11th Five Year Plan (2013-2017) and recommendations such as increased research on the red panda, capacity building and eco-friendly tourism have been incorporated. However, there is still a lack of funds to implement long-term research and advocacy programmes for the red panda, and in Bhutan it continues to be threatened by habitat destruction from developmental activities and the felling of trees for construction timber. Monitoring of anthropogenic impacts on the red panda should therefore continue to be a priority.

\section{Acknowledgements}

We thank Bhutan's Department of Forests and Park Services particularly Director Karma Drukpa, for supporting this research, the Chief Forest Officers and park management of Jigme Dorji and Thrumshingla National Parks for field assistance, and Kesang Dorjee from Sakteng Wildlife Sanctuary for sharing unpublished data. This project was funded by the Critical Ecosystem Partnership Fund of WWF-Bhutan, with support from Rotterdam Zoo, Columbus Zoo, Bhutan's Ugyen Wangchuck Institute of Environmental Conservation, and a Prince Bernhard Scholarship from WWF International.

\section{References}

Adhikari, A. (2010) An ecological overview of the red panda. The Initiation, 3, 149.

Choudhury, A. (2001) An overview of the status and conservation of the red panda Ailurus fulgens in India, with reference to its global status. Oryx, 35, 250-259.

CITES (2010) Convention on International Trade in Endangered Species of Wild Fauna and Flora: The CITES Appendices. UN Environment Programme, Geneva, Switzerland. Http://www.cites. org [accessed 10 December 2010].

Deem, S.L., Spelman, L.H., Yates, R.A. \& Montall, R.J. (2000) Canine distemper in terrestrial carnivores: a review. Journal of Zoo and Wildife Medicine, 4, 441-451.

Dorjee, K. (2009) Final Critical Ecosystem Partnership Fund Report: Conservation and Management of the Red Panda Ailurus fulgens in Sakteng Wildlife Sanctuary, Bhutan. Unpublished Report to WWF Bhutan, Thimphu, Bhutan.

DorjI, S. (2009) Final Critical Ecosystem Partnership Fund Report: Distribution and Conservation Status of the Red Panda Ailurus fulgens in Bhutan with Reference to Jigme Dorji and Thrumshingla National Parks. Unpublished Report to WWF Bhutan, Thimphu, Bhutan.

Dorji, S., Vernes, K. \& Rajaratnam, R. (2011) Habitat correlates of the red panda in the temperate forests of Bhutan. PLoS ONE, 6(10), 1-11. 
Gittleman, J.L. (1988) Behavioral energetics of lactation in a herbivorous carnivore, the red panda (Ailurus fulgens). Ethology, 79, 13-24.

Glatston, A.R. (1994) The Red Panda, Olingos, Coatis, Raccoons, and their Relatives: Status Survey and Conservation Action Plan for Procyonids and Ailurids. IUCN, Gland, Switzerland.

Gurung, D.B. \& Scholz, R.W. (2008) Community-based ecotourism in Bhutan: expert evaluation of stakeholder-based scenarios. International Journal of Sustainable Development and World Ecology, 15, 397-411.

Han, Z.X. \& Hu, J.C. (2004) Status and protection of the red panda. Bulletin of Biology, 39, 7-9.

Jiandong, Y., Zejun, Z., Ming, L.I., Jinchu, H.U. \& Fuwen, W.E.I. (2006) Home range of red pandas (Ailurus fulgens) in Fengtongzhai Nature Reserve, Sichuan, China. Acta Theriologica Sinica, 12, 13-17.

Johnson, K.G., Schaller, G.B. \& Jinchu, H. (1988) Comparative behavior of red and giant pandas in the Wolong Reserve, China. Journal of Mammalogy, 69, 552-564.

Kuenselonline (2010) Tourism and Tariff. Http://www. kuenselonline.com/2011/?p=1654 [accessed 30 November 2010].

Li, M., Wei, F.W., Goossens, B., Feng, Z.J., Tamate, H.B., Bruford, M.W. \& Funk, S.M. (2005) Mitochondrial phylogeography and subspecific variation in the red panda (Ailurus fulgens): implications for conservation. Molecular Phylogenetics and Evolution, 36, 78-89.

LiAnG, S.P. \& Z ZANG, L.X. (1987) A comparison of the primary structures of lactate-dehydrogenase isozymes $\mathrm{M}_{4}$ from giant panda, red panda, black bear and dog. Scientia Sinica-Series B: Chemical, Biological, Agricultural, Medical and Earth Sciences, $30,270-282$.

Mahato, N.K. (2004) Status of the red panda (Ailurus fulgens) in the Kangchenjunga region of Nepal. Tigerpaper, 31, 7-9.

Messerchmidt, D., Temphel, K.J., Davidson, J. \& Incoll, W.D. (2001) Bamboo in the High Forest of Eastern Bhutan: A Study of Species Vulnerability. International Centre for Integrated Mountain Development, Kathmandu, Nepal.

Ministry of Agriculture (2000) Renewable Natural Resources Census Report. Thimphu, Bhutan.

Nath, A.J. \& Das, A.K. (2010) Western Arunachal Pradesh offering prime home to the endangered red panda. Current Science, 99, 155

National Statistics Bureau of Bhutan (2009) Statistical Yearbook of Bhutan. National Statistics Bureau, Royal Government of Bhutan, Thimphu, Bhutan.

Norbu, L. (2000) Cattle grazing-an integral part of broadleaf forest management planning in Bhutan. MSc thesis, Swiss Federal Institute of Technology, Zurich, Switzerland.

Pradhan, S., SAHA, G.K. \& KhAN, J.A. (2001a) Ecology of the red panda Ailurus fulgens in the Singhalila National Park, Darjeeling, India. Biological Conservation, 98, 11-18.

Pradhan, S., SAHA, G.K. \& Khan, J.A. (2001b) Food habits of red panda Ailurus fulgens in the Singhalila National Park, Darjeeling, India. Bombay Natural History Society, 98, 224-230.

Rabinowitz, A. \& Khaing, S.T. (1998) Status of selected mammal species in North Myanmar. Oryx, 32, 201-208.

Rajaratnam, R., Pang, C. \& Lackman-Ancrenaz, I. (2008) Ecotourism and indigenous communities: the lower Kinabatangan experience. In Tourism at the Grassroots: Villagers and Visitors in the Asia-Pacific (eds J. Connell \& B. Rugendyke), pp. 236-255. Routledge, London, UK.

REID, D.G., Hu, J.C. \& YAN, H. (1991) Ecology of the red panda Ailurus fulgens in the Wolong Reserve, China. Journal of Zoology, 225, 347-364.

RNR Engineering Division (2008) Farm Roads and Power Tiller Tracks of Bhutan. Ministry of Agriculture, Thimphu, Bhutan.
Roberts, M.S. \& Gittleman, J.L. (1984) Ailurus fulgens. Mammalian Species, 222, 1-8.

Roder, W., Gratzer, G. \& Wangdi, K. (2002) Cattle grazing in the conifer forests of Bhutan. Mountain Research and Development, 22, 368-374.

Royal Government of Bhutan (2009) Bhutan Biodiversity Action Plan 2009. National Biodiversity Center, Thimphu, Bhutan.

Tshering, K. (2009) Agriculture and usage of natural resources in Bhutan. Journal of the Faculty of Agriculture, Shinshu University, 45, $33-42$.

Wang, X., Choudhury, A., Wozencraft, C. \& Zaw, T. (2008) Ailurus fulgens. In IUCN Red List of Threatened Species v. 2011.2. Http://www.iucnredlist.org [accessed 25 May 2012].

Wei, F., Feng, Z., WANG, Z. \& Li, M. (1999a) Feeding strategy and resource partitioning between giant and red pandas. Mammalia, 63, 417-429.

Wei, F., Feng, Z., Wang, Z., Zhou, A. \& Hu, J. (1999b) Nutrient and energy requirements of the red panda (Ailurus fulgens) during lactation. Mammalia, 63, 3-10.

Wei, F.W., Feng, Z.J., Wang, Z.W. \& Hu, J.C. (1999c) Current distribution, status and conservation of wild red pandas Ailurus fulgens in China. Biological Conservation, 89, 285-291.

Wei, F.W., Feng, Z.J., Wang, Z.W. \& Hu, J.C. (2000a) Habitat use and separation between the giant panda and the red panda. Journal of Mammalogy, 81, 448-455.

Wei, F.W., Feng, Z.J., Wang, Z.W., Zhou, A. \& Hu, J.C. (1999d) Use of the nutrients in bamboo by the red panda (Ailurus fulgens) Journal of Zoology, 248, 535-541.

Wei, F.W., Wang, Z.W., Feng, Z.J., Li, M. \& Zhou, A. (20oob) Seasonal energy utilization in bamboo by the red panda (Ailurus fulgens). Zoo Biology, 19, 27-33.

Williams, B.H. (2003) Red pandas in eastern Nepal: how do they fit into ecoregional conservation of the eastern Himalayas. Conservation Biology in Asia, 16, 236-250.

YANG, Q. (2008) Distribution of the red panda in Qionglai Mountains of Sichuan Province. Zoological Research, 29, 546-552.

Yonzon, P.B. \& Hunter, M.L. (1987) Ecological Study of the Red Panda in Nepal-Himalayas. Red Panda Conference. Royal Rotterdam Zoological and Botanical Gardens, Rotterdam, The Netherlands.

Yonzon, P.B. \& Hunter, M.L. (1991a) Cheese, tourists, and red pandas in the Nepal Himalayas. Conservation Biology, 5 , 196-202.

Yonzon, P.B. \& Hunter, M.L. (1991b) Conservation of the red panda Ailurus fulgens. Biological Conservation, 57, 1-11.

Yonzon, P.B., Jones, R. \& Fox, J. (1991) Geographic information systems for assessing habitat and estimating population of red pandas in Langtang National Park, Nepal. Ambio, 20, 285-288.

Zhang, Z.J., Hu, J.C., YANG, J.D., Li, M. \& WeI, F.W. (2009) Food habits and space-use of red pandas Ailurus fulgens in the Fengtongzhai Nature Reserve, China: food effects and behavioural responses. Acta Theriologica, 54, 225-234.

ZhanG, Z.J., Wei, F.W., Li, M. \& Hu, J.C. (2006) Winter microhabitat separation between giant and red pandas in Bashania faberi bamboo forest in Fengtongzhai Nature Reserve. Journal of Wildlife Management, 70, 231-235.

\section{Biographical sketches}

SANGAY DORJI is interested in the ecology and conservation of Himalayan mammals, the design and management effectiveness of biological corridors, and promoting community-based biodiversity conservation. $\mathrm{He}$ is currently the National Coordinator of the 
Biological Corridor Network in Bhutan, having worked in various national parks in Bhutan for 12 years. RAJANATHAN RAJARATNAM is a biogeographer with research experience and interest in small carnivores, primates and biodiversity conservation in the agricultural landscape of Borneo. KARL VERNES has research interests in mammal ecology and conservation, with a focus on the ecology of threatened mammals. He has previously worked in Bhutan on human-wildlife conflict involving large predators. All three authors are currently collaborating on biodiversity surveys within the Biological Corridor Network of Bhutan. 